\section{Controlled-temperature Treatments with Low-cost, Off-the-shelf Equipment for Bud or Seed Forcing Experiments}

\author{
Douglas G. Bielenberg ${ }^{1}$ \\ Department of Biological Sciences, Clemson University, Clemson, SC 29634- \\ 0314
}

\author{
Ksenija Gasic \\ Department of Plant \& Environmental Sciences, Clemson University, \\ Clemson, SC 29634-0310
}

Additional index words. dormancy, germination, heat, growing, degree, tree, flowering, bloom

\begin{abstract}
Inexpensive plug-and-play temperature controllers have recently become available. These allow a chest freezer to be programmed easily to hold a desired set point across a range of biologically relevant temperatures. Installation can be completed in a few minutes using consumer-grade chest freezers. We used these temperature controllers to create five temperature-controlled chambers at $12,14,16,18$, and $20^{\circ} \mathrm{C}$. We demonstrated the use of these controlled-temperature chambers with two biologic assays: floral budbreak of peach [Prunus persica (L.) Batsch] stem cuttings and germination of sunflower (Helianthus annuus L.) seeds. We used the budbreak and germination rates at multiple temperatures to estimate base temperatures and thermal time requirements for development.
\end{abstract}

Characterizing the regulation of development by temperature requires controlled exposure of replicate plants (whole or in part) to multiple temperature environments simultaneously. Experiments with seeds or other small plant segments can be performed on a thermal gradient table, which can generate many temperatures simultaneously (Welbaum et al., 2016). However, experiments involving larger plant parts, such as cut stems used in forcing experiments of woody perennials, require temperature control of a larger three-dimensional volume, such as an environmental chamber (Anzanello and Biasi, 2016; Primack et al., 2015). Inexpensive access to the number of environmental chambers needed for the parameterizing temperature response curves for development is not common and can limit the scope of experiments. Modifications of consumer-grade freezers or refrigerators to bypass built-in temperature controllers with programmable controllers have been used for a variety of applications, but require a minimum level of technical ability to wire and install safely (Hutten-Czapski, 2017). Newly available plug-and-play temperature controllers allow conversion of a standard

Received for publication 10 Oct. 2018. Accepted for publication $23 \mathrm{Jan} .2019$.

Funding for this project was provided from the Clemson University Creative Inquiry program and a grant to Douglas Bielenberg and Ksenija Gasic from the U.S. Department of Agriculture Specialty Crop Block Grant Program (agreement AM170100XXXXG034) through the South Carolina Department of Agriculture.

We thank Rosa Kome and Marcellus Washington for their invaluable assistance with data collection. ${ }^{1}$ Corresponding author. E-mail: dbielen@clemson. edu.
Co., Ltd., Shenzhen, P.R. China; https:// www.ink-bird.com/products-temperaturecontroller-itc308.html) was installed between each of five $17.5-\mathrm{ft}^{3}$-capacity Kenmore chest freezers (Sears Brands, LLC, Chicago, IL) and the building electrical supply. Freezers were plugged into the cooling outlet of the ITC308; the heating outlet was left unused. The ITC-308 controllers were programmed with one of five set points $\left(12,14,16,18\right.$, or $\left.20^{\circ} \mathrm{C}\right)$, with a cooling differential of $0.5{ }^{\circ} \mathrm{C}$. The thermal probe for each ITC-308 was installed at the approximate center of the freezer volume by securing it to a wooden post. Four 3.5gal water containers (Waterbrick Intl., FL) were placed in the bottom of each freezer to serve as temperature ballast. One 8-in desktop fan (Utilitech; Lowe's Home Improvement, Mooresville, NC) was placed in each freezer on the internal shelf created by the compressor volume and supplied power through an extension cord. Fans were aimed at the front internal wall of the chamber to circulate air from the cooling surface. Chamber (freezer) temperatures were recorded with OM-92 data loggers (Omega Engineering, Egham, Surrey, UK) at 10-min intervals. The room temperature where the chambers were located for the duration of the experiments ranged between 15 and $20^{\circ} \mathrm{C}$.

Peach stem cuttings (accession 'A209') were collected from the Clemson University Musser Fruit Research Center on 8 Jan. 2018. 'A209' is a low-chill peach genotype described by Zhebentyayeva et al. (2013). Five stems per temperature treatment were trimmed to $\approx 25 \mathrm{~cm}$ in length and placed in two-times-strength Floralife ${ }^{\circledR}$ Crystal Clear (Floralife, Walterboro, SC). Budbreak progress was observed three times per week until no changes occurred for three observations. Budbreak fraction was calculated from the number of initial floral buds present on the stems.

Forty sunflower seeds (Carolina Biological Supply Co., Burlington, NC) per chamber were sown into 1020 plant flat trays without holes containing moist Fafard ${ }^{\circledR}$ Germination Mix (Sun Gro ${ }^{\circledR}$ Horticulture, Agawam, MA) on 30 Apr. 2018 and were observed daily. Trays were covered with a clear plastic lid to prevent drying; trays did not require rewatering during the experiment. Germination fraction was normalized to the maximum germination fraction across the five temperatures.

\section{Results and Discussion} variation in the base temperature for vegetative budbreak within fruit tree species, demonstrating the need to develop methods to test our assumptions with widespread screening of germplasm (Anzanello and Biasi, 2016). A base temperature of $6.7^{\circ} \mathrm{C}$ is often used in germination modeling in sunflower, but varieties have been shown to have lower base temperatures (Khalifa et al., 2000).

\section{Materials and Methods}

One Inkbird ITC-308 Outlet Thermostat Temperature Controller (Inkbird Tech.
All chambers showed a consistent oscillation representing the on/off cycles determined by the temperature controllers (Fig. 1). With the cooling differential set at $0.5{ }^{\circ} \mathrm{C}$, freezers were only supplied power when the temperature reached the set point $+0.5{ }^{\circ} \mathrm{C}$; the power was turned off when the temperature fell below the set point. Average chamber temperatures $(11.8,13.6,15.9,17.8$, and $20.1{ }^{\circ} \mathrm{C}$ ), monitored by data loggers, were slightly different from the temperature controller set points $\left(12,14,16,18\right.$, and $\left.20^{\circ} \mathrm{C}\right)$ despite placement of the data loggers near the 


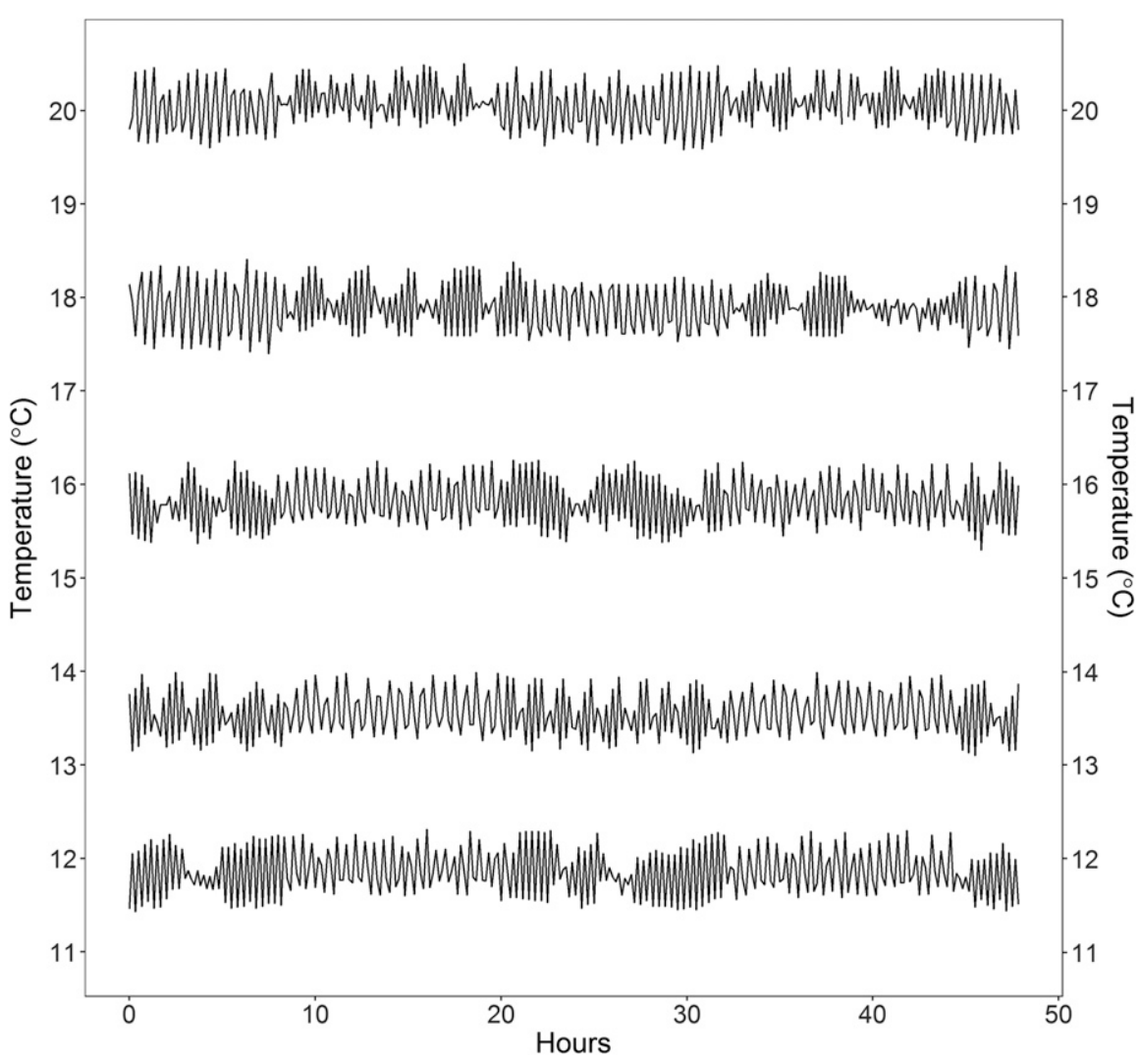

Fig. 1. Forty-eight-hour time course of temperature recordings (at 10-min intervals) from chest freezers with installed ITC-308 Outlet Temperature Controllers (Inkbird Tech. Co., Ltd., Shenzhen, P.R. China). Chambers were not opened during the $48-\mathrm{h}$ period. Temperature set points and cooling differentials set as described in Materials and Methods.

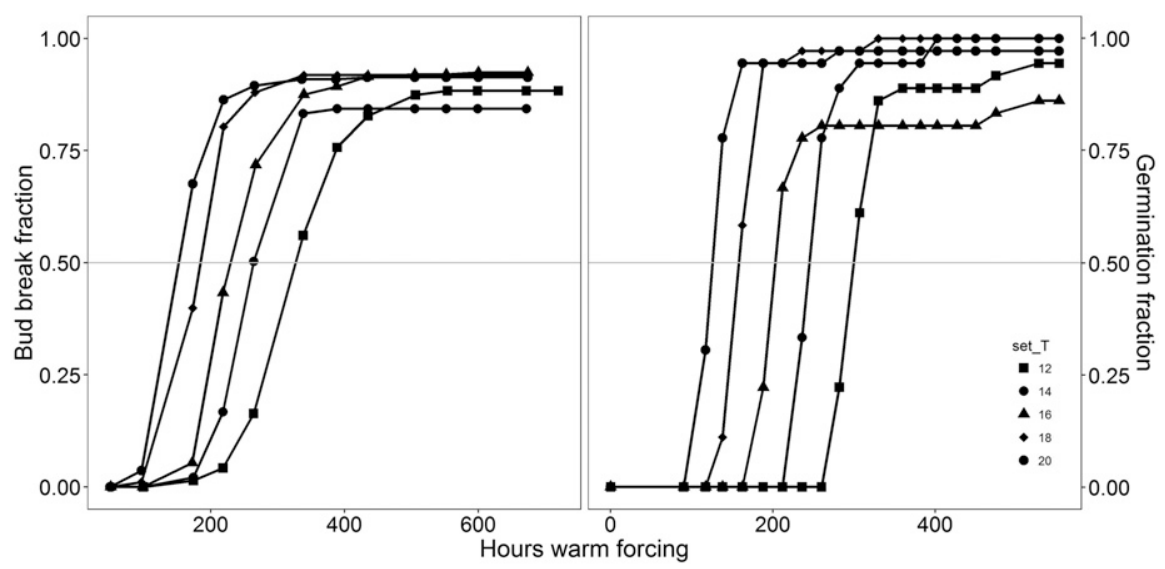

Fig. 2. Peach floral budbreak (left) or sunflower seed germination (right) fraction at constant forcing temperatures. The gray line indicates the median budbreak or germination.

controller temperature probe (Fig. 1). This was a result of a slight overshooting of the temperature past the set point on the cooling cycle. Observation of actual average temperature in each chamber could be used to adjust the temperature set point to achieve the desired environment.

The effectiveness of the chambers to investigate the effect of temperature on developmental rates was assessed with two biological assays: budbreak progress of peach floral buds warm-forced at different temperatures and suboptimal temperatures can be used easily to calculate an estimated base temperature for that developmental response (Anzanello and Biasi, 2016; Trudgill et al., 2005). We calculated the hours to reach median $(50 \%)$ budbreak/germination at each temperature treatment by linear interpolation between the observations bracketing the median value. Expressing hours to median budbreak/germination at each temperature as a rate (per hour) produced a linear relationship with temperature (Fig. 3). Extrapolating this linear relationship to the point where development rate is expected to be zero (i.e., solving for $x$ where $y=0$ ) provided an estimate of the minimum or base temperature required for development (Fig. 3). We used our data to calculate a base temperature of $4.75{ }^{\circ} \mathrm{C}$ for median floral budbreak in peach variety 'A209' (Fig. 3). This is close to the commonly used base temperature for warmforcing of blooms in Prunus sp. of $4{ }^{\circ} \mathrm{C}$ (Anderson et al., 1986). The linear relationship up to $20^{\circ} \mathrm{C}$ also indicates that we had not yet reached the optimum temperature for floral development in peach, which has been reported to be $25{ }^{\circ} \mathrm{C}$ (Anderson et al., 1986). We calculated a base temperature for the sunflower seeds used in this experiment to be $6.3{ }^{\circ} \mathrm{C}$, which falls within the range of reported base temperatures $\left(3.3\right.$ to $6.7^{\circ} \mathrm{C}$ ) for sunflower varieties (Khalifa et al., 2000).

The ITC-308 is available through online retailers for about US\$40 as of 2018. In the configuration we used in our study, with 17.5$\mathrm{ft}^{3}$ freezers, the total cost of each chamber with all components mentioned in Materials and Methods was about US\$718 as of 2018, of which the predominant expense was the chest freezer at US\$500. Costs per chamber will be variable because consumer-grade chest freezers come in a wide variety of sizes. The desired chamber volume is dictated by the number and physical size of the samples to be tested. If either of these is small, costs per chamber can be reduced significantly by decreasing the size of the chest freezer used. Likewise, the electrical costs and electrical circuit demands of these chambers are dependent on the ambient temperature, internal temperature setting, and/or size of the chest freezer used. As with any electrical appliances, care should be taken to avoid exceeding the circuit capacity if all appliances draw current simultaneously.

These controllers will allow horticulturists, agronomists, foresters, and educators to design and perform experiments when multiple controlled-temperature environments are required without access to specialized facilities or skills. Off-the-shelf, easy-to-use components offer the potential to expand greatly the community of researchers who are able to incorporate temperature physiology into their investigations of plant development and phenology - particularly workers outside of traditional research institutions. Without humidity control or high-intensity lighting, these controllers will be of the most use in warmforcing experiments such as budbreak or germination, when photosynthetic growth is not 


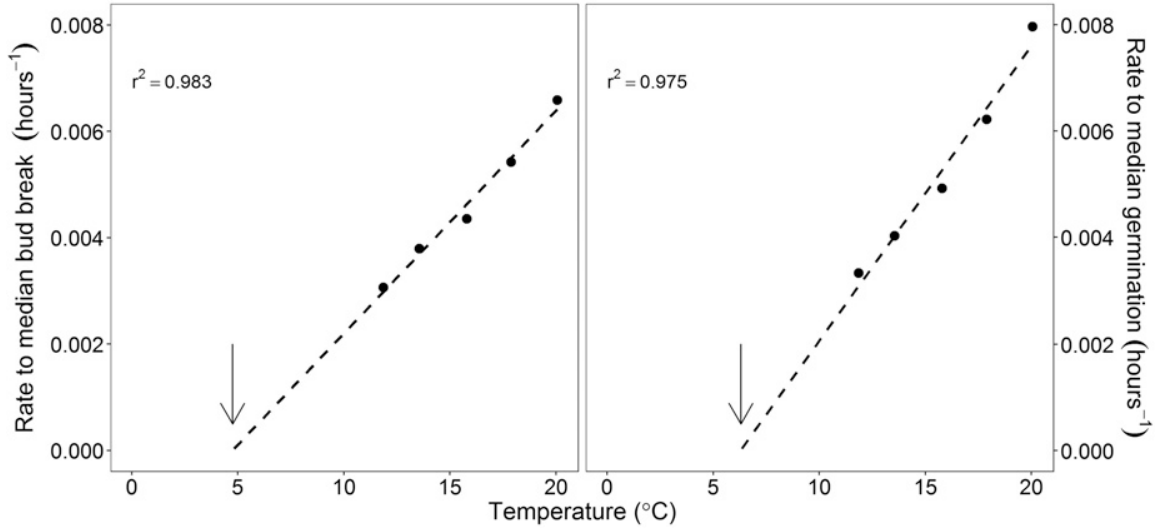

Fig. 3. Rate of median floral budbreak (left) or median sunflower seed germination (right) at constant forcing temperatures. Regression lines are extended to the horizontal axes to indicate the $\mathrm{x}$-axis value where the development rate is estimated to be zero $\left(\mathrm{T}_{\mathrm{b}}\right.$, indicated by arrows).

required. Lighting with light-emitting diodes for photoperiod signaling can be added easily if desired. Finally, chamber temperatures should be validated independently of the controllers to allow adjustment of set points for accuracy.

\section{Literature Cited}

Anderson, J.L., E.A. Richardson, and C.D. Kesner. 1986. Validation of chill unit and flower bud phenology models for 'Montmorency' sour cherry. Acta Hort. 184:71-78.
Anzanello, R. and L.A. Biasi. 2016. Base temperature as a function of genotype: A foundation for modeling phenology of temperate fruit species. Semin. Cienc. Agrar. 37:1811-1826.

Hutten-Czapski, P. 2017. From beer brewing to vaccine stability. Can. Fam. Physician 63:544-545.

Khalifa, F.M., A.A. Schneiter, and E.I. Eltayeb. 2000. Temperature-germination responses of sunflower (Helianthus annuus L.) genotypes. Helia 23:97-104.

Primack, R.B., J. Laube, A.S. Gallinat, and A. Menzel. 2015. From observations to experiments in phenology research: Investigating climate change impacts on trees and shrubs using dormant twigs. Ann. Bot. 116:889-897.

Trudgill, D.L., A. Honek, D. Li, and N.M. Van Straalen. 2005. Thermal time - concepts and utility. Ann. Appl. Biol. 146:1-14.

Welbaum, G.E., O.S. Khan, and N.H. Samarah. 2016. A gusseted thermogradient table to control soil temperatures for evaluating plant growth and monitoring soil processes. J. Vis. Expt. 116:e54647.

Zhebentyayeva, T.N., S. Fan, A. Chandra, D.G. Bielenberg, G.L. Reighard, W.R. Okie, and A.G. Abbott. 2013. Dissection of chilling requirement and bloom date QTLs in peach using a whole genome sequencing of sibling trees from an F2 mapping population. Tree Genet. Genomes 10:35-51. 